таксис также допускает трансформации в звене характеристики без особой потери смысла. Например:

Sie war gar nicht und lebenslustig. Sie wohnte mit ihrer Mutter zusammen, an der sie hing [7, S. 19].

Или:

Sie wohnte mit ihrer Mutter zusammen, an der sie hing. Sie war gar nicht und lebenslustig.

Также представляется важным отметить, что для звена характеристики не является существенной связь с тематизированным текстом. Синтаксическое оформление звена характеристики значительно не отличается от оформления звеньев других КРФ. Его реализация осуществляется главным образом в сложноподчинённом предложении с придаточным определительным [3, с. 33]. Данный тип предложения встречается и в приведённом выше примере (Sie wohnte mit ihrer Mutter zusammen, an der sie hing).

Таким образом, можно сделать вывод, что в модели звена характеристики выделяется ряд признаков, позволяющих рассматривать её как самостоятельную КРФ, а не отождествлять её исключительно с описанием или рассуждением.

$$
* * *
$$

1. Брандес М.П. Рассуждение как конструктивный элемент информационной формы текста // Учёные записки. Серия: Лингвистика. Межкультурная коммуникация. Перевод. - Курск: изд-во РОСИ, 1999. -89 c.

2. Клочков А.В. Особенности функционирования композиционно-временных форм в структуре текста художественного произведения // Актуальные проблемы филологии и педагогической лингвистики. 2019. № 1. С. 119-127.

3. Россихина Г.Н. Как строится немецкая речь. - М.: Высшая школа, 1992. - 109 с.

4. Россихина Г.Н. Функциональное взаимодействие языковых средств в композиционно-речевом звене (на материале немецкого языка) // Филологические науки. - М.: Высшая школа, 1994. - С. 89-97.

5. Bentz H. Licht von jenseits der Straße. - Im Bertelsmann Lesering, 1960.

6. Böll H. Irisches Tagebuch. Deutscher Taschenbuch Verlag, 1962.

7. Döblin A. Die beiden Freundinnen und ihr Giftmord. Suhrkamp Verlag, 1971.

8. Fischer M-L. Elbchaussee. Goldmann Verlag, 1990.

9. Hesse H. Narziß und Goldmund. Suhrkamp Taschenbuch, 1990.

10. Mann K. Mephisto. Roman einer Karriere. Rowohlt Taschenbuch Verlag Reinbek bei Hamburg, 1995.

11. Mendt D. Aller guten Dinge sind vier. Union Verlag Berlin, 1968.

12. Musil R. Ausgewählte Prosa. - М.: Прогресc, 1980.

13. Süskind P. Das Parfum. Die Geschichte eines Mörders. Diogenes Taschenbuch, 1994.

\title{
Кюрегян А.Л. \\ Развитие парадигмы сложного предложения с временной предикативной единицей при настоящем времени в главной части на протяжении новоанглийского языка
}

ФГБОУ ВО «Самарский государственный технический университет» (Россия, Самара)

doi: 10.18411/lj-05-2021-272

\section{Аннотация}

Данная статья посвящена исследованию парадигмы сложного предложения (CП) в новоанглийском языке. Новоанглийский период является одним из этапов в долгой истории английского языка, поэтому для отражения изменений в системе языка в разные этапы его существования в истории английского языка принято выделять определённые периоды.

В работе были рассмотрены все возможные сочетания видо-временных форм в сложном предложении с временной предикативной единицей (ПЕ) при настоящем 
времени глагола в главной ПЕ. В абсолютном большинстве случаев настоящему времени в главной ПЕ также соответствует настоящее время и это свидетельствует, с одной стороны, об обыденной, повседневной тематике разговора, а с другой - о стремлении собеседников к использованию простейших видо - временных форм глагола в сложном предложении в данном стиле.

Ключевые слова: новоанглийский период, сложное предложение, временная предикативная единица.

\section{Abstract}

This article is devoted to the study of the complex sentence (SP) paradigm in New English. The New English period is one of the stages in the long history of the English language. In order to reflect the changes in the language system at different stages of the English language it is customary to allocate certain periods.

The paper considers all possible combinations of time forms in a complex sentence with a time predicative unit (PU) in the present tense. The present tense in the main PU is most wildly used and this indicates, on the one hand, the ordinary, everyday topic of conversation, and on the other - the desire of the interlocutors to use the simplest time forms of the verb in a complex sentence in this style.

Key words: new English period, compound sentence, time predicative unit.

Настоящая работа представляет собой исследование парадигмы сложного предложения (СП) в новоанглийском языке. Новоанглийский период является одним из этапов в долгой истории английского языка, поэтому для отражения изменений в системе языка в разные этапы его существования в истории английского языка принято выделять определённые периоды.

Как отмечают грамматисты, «формы неопределённого вида (Simple) не характеризуют действия со стороны характера его протекания, они только констатируют его наличие (или отсутствие) и помещают его в тот или иной временной отрезок» [1]. Форма Present Simple, естественно, помещает действие во временной интервал настоящего. Посмотрим, какие же при этом имеют место соотношения видовременных форм в СП с временной предикативной единицей (ПЕ).

Первый вид соотношения форм глаголов- сказуемых главной и зависимой ПЕ можно представить как "Present Simple - Present Simple".

Этот вид соотношения относится к числу ведущих во всех подпериодах разговорной речи (РР) новоанглийского языка. В РНА подпериод число таких примеров составляет 84 \% исследуемого материала, в СНА $-76,5 \%$ и в СА $-85 \%$.

Такое соотношение времён используется, во-первых, для констатации регулярного, обыденного положения вещей. Например: ранненовоанглийский (PHA): But cruel are the times, when we are traitors, and do not know ourselves. (Sh, TT, 148)

средненовоанглийский (СНА). When a girl finds a fellow's outside to her taste, she sets about guessing the rest of his furniture. (G, Sh, 62)

Эта же оппозиция используется для выражения жизненных наблюдений, философских изречений. Приведём пример:

PHA: All beasts are happy when they die. (M, TT, 182)

CHA: A man is tired of getting the better before his wife is tired of loosing the victory.

Необходимо отметить средства, за счёт которых достигается обобщение, помимо значения самой глагольной формы: во-первых, использование обобщённо - личных местоимений: you, we, they и существительного собирательного значения «people».

PHA: Now you begin, when crimes are done. $(\mathrm{J}, 107)$

CHA: And betray us when we most want to excel. (G,Sh, 48) 
- But then, when people put down their weapons, it doesn't mean they've neccessarily stopped fighting. (MEP,128)

Наряду с вышеназванными средствами для обозначения обобщения употребляется также неопределённый артикль - a, числительное - one, местоимения some, any:

PHA: Yet what can it when one can not repent? (Sh, TT, 61)

- For some must watch, while some must sleep. (Sh, TT, 56)

CHA: When a husband entertains a groundless suspicion of his wife, the original compact is broken. (Sheridan, 278)

Обобщение также достигается при помощи употребления существительного men, имеющего собирательное значение. Приведём примеры:

PHA: For they are friends that help to wean my state, till men and kingdoms help to strengthen it. (M, TT, 11)

Соотношение «Present Simple - Present Simple» также используется и для выражения регулярных, повторяющихся действий. В таких предложениях, как правило, наблюдается наличие союза -whenever, наречий частотности - always, never, sometimes.

PHA:I always smile to think when this field is fought. (M, TT, 100)

- Whenever I ask, I am not to be put off. (M, TT, 37)

CHA: I never see you when you are in spirits. $(\mathrm{G}, \mathrm{Sh}, 53)$

Это соотношение может использоваться для передачи одновременных и разновременных действий. Одновременность как грамматическое явление языка имеет своё семантическое содержание: действий главного и придаточного предложений протекают в один и тот же момент. [2]

Одновремённость действий подчёркивается за счёт использования временного союза while. Напрмер:

PHA: And in my blood wash all your hands at once, while I sit smiling to behold the sight. (M, TT, 91)

CHA: While he is with them I may go out with safety.(Sheridan, 110)

Как видно из приведённых примеров, действия сложноподчинённого предложения замыкаются в пределах одной временной сферы и это отражено в грамматической монотемпоральности главной и придаточной частей предложения [2].

Однако встречаются случаи, когда соотношение «Present Simple - Present Simple» употребляется для выражения разновремённых действий, то есть действия во времени их протекания не совпадают, что подчёркивается временными союзами till, before.

PHA: He dies that touches any of this fruit till I and my affairs are answered. (Sh, 42)

CHA: I' $\underline{m}$ not a complete rogue before I turn the corner.(Sheridan, 260)

Второй вид соотношений в сфере настоящего представлен оппозицией «Present Simple- Present Perfect».

Наряду c Present Simple, в придаточной части сложного предложения может употребляться и видо - временная форма Present Perfect, число таких примеров в XVI веке равно $6 \%$, в XVIII - 8,5\% и в современном языке- $7 \%$ от общего числа примеров в сфере настоящего.

Перфект настоящего времени передаёт завершённость действия к моменту речи; он не требует особого указания в тексте посредством обстоятельства времени, хотя оно при желании и может быть указано.

Перфект предельных глаголов передаёт достижение предела действия, при необходимости акцентировать его. Напомним, что предельные глаголы - «это глаголы, обозначающие такое действие, которое по достижении предела не может продолжаться» [1, с.49], т.е. действие исчерпывает себя. Таковы глаголы, например, to 
meet, to make, to catch, to come, to arrive, to discover, to finish, to give. Они достаточно активно используются в РР новоанглийского периода развития английского языка:

PHA: I perceive only that you answer one gentleman before he has finished, and the other before he has well begun. (Sh, As, 75)

CHA: Why, than, you wonder before I have given you a proof of it?(Sheridan, 212)

Зарегистрированы также и перфектные формы непредельных глаголов, которые не содержат указание на ограниченность протекания обозначаемого ими действии; в этом случае "предел может мыслиться как поставленный извне.., но не вытекающий из семантики глагола: to sleep, to live, to belong, to enjoy, to think". Например:

PHA: What dreams come true, when we have thought of this. (Sh, TT,46)

Употребление перфекта непредельных глаголов в придаточном предложении означает прекращение действия к моменту речи, без достижения предела.

Наряду с вышеописанными сочетаниями видо - времённых форм в главном и придаточном предложениях, встречаются также употребления разряда Present Perfect в главной части и Present Simple в придаточной. Такое сочетание встречается крайне редко ( $2 \%$ от группы примеров в сфере настоящего), но и они имеют место только в материале РНА периода. Например:

- $\quad$ Hath spread his colours to our high disgrace, while you faint - hearted base Egyptans lie slumbering on the flow banks on Nile. (M, TT, 40)

- And oft hath warn ' $d$ thee to be still in field, when he himself admidst the thickest troops. (M, TT, 100)

Употребление формы Present Perfect в главной части означает завершение действия и наличие результата, то есть, действие в главной части предшествует действию в придаточной.

- When a man thanks me heartly, I have given him a penny. (Sh, As, 38)

В нашем материале отмечены соотношения, когда в главной ПЕ употреблена форма Present Simple, а в зависимой Present Continuous. Такое соотношение также не типично для РP новоанглийского периода. Эта оппозиция используется в экспрессивной функции, когда при параллельных действиях форма Continuous подчёркивает процессуальность, непрерывность нежелательного действия. Например:

PHA: And I think she never appears to such advantage as when she is doing everything in her power to plague me.(M, TT, 28)

CHA: But one cannot help when the house is going out of the windows.(V,G,178)

Наряду с вышеописанными сочетаниями видо - времённых в главном и придаточном предложениях, встречаются также употребления разряда Present Continious в главной части и Present Simple в придаточной. Такое сочетание отмечено в материале средненовоанглийского подпериоде (2\% от группы примеров в сфере настоящего) и в современном материале (6\%):

Действие, выраженное длительным разрядом, в этом случае мыслится как непостоянное, ограниченное в отрезке времени, которое уточняется временным придаточным.

And when he looks at me - What'she thinking? (MED, 137)

Таким образом, придаточное времени здесь выступает как временной центр, указывающий на параллельное протекание другого действия.

Последний пример интересен с точки зрения построения. Предложение разделено посредством «тире». Такой процесс называется «парцеляция», то есть содержание высказывания реализуется не в одной, а в двух или нескольких интонационно - смысловых речевых единицах [3].

Итак, выше были рассмотрены все случаи, когда и в главной, и в зависимой временной ПЕ сказуемые выражены видо - временными формами настоящего.

Соотношение времён Present-Past составляет 7\% от примеров в сфере настоящего в ранненовоанглийском подпериоде, $13 \%$ - в среднеанглийском подпериоде и только $1 \%$ - в современном языке. Во всех подпериодах встречается оппозиция 
«Present Simple - Past Simple», составляющая 5 \% - PHА, 2\% - СНА. Например: РНА: They were all like one another as halfpence are; every one fault seems monstrous till his fellow fault came to match it. (Sh, As, 55)

CHA: I remember when poverty began to show her face. $(\mathrm{L}, 299)$

Таким образом, во временном придаточном описываются события, уже имевшие место, которые вспоминаются говорящим - об этом свидетельствует семантика сказуемого главной части - to remember, to put in mind, to imply.

В двух подпериодах новоанглийского языка встречается также соотношение «Present Perfect -Past Simple» (XVI - XVII вв. - 2 \% от числа примеров в сфере настоящего, XVIII в. - 9\%):

CHA: My sister has been with her aunt since she was a child...(G, 30)

Из приведённых примеров видно, что форма Present Perfect в этих случаях передаёт длительное действие, то есть выступает в роли Perfect Continious, которое не может употребляться с глаголом to be; придаточное времени вводится союзом since и обозначает начальный момент действия или процесса, о котором идёт речь в главной части.

Соотношение «Present Perfect Continuous - Past Simple» зарегистрировано впервые в материале XVIII века: You have been dosing me since I was born. (G,Sh, 53)

В этом случае в главной части выражается длительное действие, а

придаточное времени передаёт его начальный момент. Форма Perfect Continuous сформировалась в языке довольно поздно, что может объяснить её отсутствие в материале ранненовоанглийского подпериода; однако эта форма не отмечена и в современном материале. Следовательно, можно предположить, что она в целом мало характерна для РР в силу её «тяжеловесности».

Итак, мы рассмотрели все возможные сочетания видо-временных форм в сложном предложении с временной ПЕ при настоящем времени глагола в главной ПЕ. В абсолютном большинстве случаев настоящему времени в главной ПЕ также соответствует настоящее время и это свидетельствует, с одной стороны, об обыденной, повседневной тематике разговора, а с другой - о стремлении собеседников к использованию простейших видо - временных форм глагола в сложном предложении в данном стиле.

$$
* * *
$$

1. Иванова И.П., Бурлакова В.В., Почепцов Г.Г. Теоретическая грамматика английского языка: Учебник/- М.: Высш. школа, 1981. С.54.

2. Дреева Дж.М., Отрошенко А.И. Особенности употребления синтетических форм настоящего и прошедшего времени в текстах четвероевангелия Библий Уиклифа, Тиндейла и короля Иакова //Филологические науки. Вопросы теории и практики. Тамбов: Грамота, 2017. № 12(78): в 4 ч. ч. 2.C. $100-104$.

3. Кюрегян А.Л., Рыбальчик О.А. Парадигматика и синтагматика как два аспекта изучения языковой системы // Актуальные проблемы теоретической и прикладной лингвистики. Сборник статей II Всероссийской научно-практической конференции. Пензенский государственный университет; Межотраслевой научно-информационный центр; Под редакцией С.С. Пашковской, Т.А. Румянцевой, Г.В. Вишневской. 2015. С. 84-86.

Лисевская А.И., Титаренко Н.В.

Трансформация падежей и склонений имени существительного от латинского до испанского языка (на материале «Cantar de mio Cid» XII)

ФГБОУ ВО «Волгоградский государственный соииально-педагогический университет» (Россия, Волгоград)

doi: 10.18411/lj-05-2021-273

\section{Аннотация}

В статье рассмотрены такие понятия как имя существительное, падеж, склонение имени существительного в латинском языке и эволюция форм 